\title{
Age of first insemination of gilts and their productivity
}

\author{
Olga Tretyakova ${ }^{1}$, Valentina Nefyodova $^{1}$, Victoria Solonnikova ${ }^{1, *}$, and Svetlana \\ Romantsova $^{1}$ \\ ${ }^{1}$ Don State Agrarian University, Persianovskiy, Krivoshlykova st., 24, Rostov region, 346493, Russia
}

\begin{abstract}
The influence of the age of the first insemination of pigs on their subsequent productivity was evaluated. In the period from 2017 to 2020, 167 pigs were inseminated in the company Plemzavod-Yubileyny in the Tyumen region, which were divided into groups. Productivity indicators were analyzed based on the number of piglets born. In 2017, 12.5 piglets were obtained in group III, where the age of the first insemination was 241-253 days, and 12.7 piglets were obtained in group VI (281-311 days). In 2018, 101 sows were farrowed out of 164 heads (groups I, II, III), 1123 piglets were received from them, 1037 live ones were received. The largest number of piglets born was observed in group IV-12.4 units. In 2019, the largest number of piglets born was observed in group III-11.4 units. In 2020, out of 181 farrowings, 135 units were received, of which 1,528 piglets, of which 1,507.5 live.
\end{abstract}

\section{Introduction}

In providing the population of Russia with meat products, a significant role is assigned to pig breeding as the most intensive and efficient branch of animal husbandry, due to the extremely valuable biological characteristics of these animals: fertility, early maturity, omnivorousness, a wide range of use of slaughter products and their long-term storage.

In recent years, the use of sows has increased significantly. For a year, they began to receive 2.4 farrowings from a sow, 20-25 piglets per uterus. However, modern genetics and innovative technologies for keeping and raising animals make it possible to obtain up to 27 28 piglets. Denmark already receives 30 piglets from one sow per year. Effective technologies of pork in-line production in large industrial complexes have been developed [2].

In this regard, the age of introduction of replacement young stock into industrial use is of great importance. Too early use of them leads to weak offspring, reduced fertility, and later - to an increase in the cost of producing piglets. The late introduction of young gilts leads to an increase in the unproductive period of sow use. It should be noted that sows play a leading role in reproduction. The level of productivity, prospects and profitability of pig breeding depend on their age and their health [1].

Considering these circumstances and their importance in breeding work with mother breeds as the main means of production, we were faced with the task of identifying the

* Corresponding author: viktoriasolonnikova@yandex.ru 
most important factors influencing the productive use of sows on the basis of available information. In this regard, the aim of the research was to study the effect of the age of the first insemination of gilts on their subsequent productivity. The following tasks were set: to group the gilts according to the age of the first insemination; determine the relationship between age and subsequent productivity; to identify the optimal age of the first insemination.

Solving the issues of assessing the reproductive value of sows are important in understanding the reproductive potential of pig herds, especially breeds such as the Large White, Landrace, which are considered classic mothers [3].

\section{Material and research methods}

Much attention of breeders and geneticists of the world is directed to the creation of mother lines of pigs with high fertility, large piglet weight at birth, strong constitution and good health and longevity (duration of use). These indicators make it possible to stabilize technological processes on the farm by reducing the cost of introducing replacement young stock, recalculating feed, and improving the quality of offspring carcasses. Sows play a leading role in reproduction. The level of productivity, the prospects for the development of pig breeding and the profitability of running the industry depend on the state of their health.

The world experience of the pig breeding industry indicates that it is difficult to combine reproductive, meat and fattening qualities in one breed due to the low efficiency of simultaneous selection for many characteristics.

The terms of the productive use of sows depend on how proliferation, milk production and the safety of the litter will change with age. You should not change the sow every 2-3 years if all her indicators remain at a high level. According to the data of domestic and foreign scientists, the productivity of queens increases every year, and then begins to gradually decrease. On average, the duration of the use of the uterus is 5-7 years or 7-8 farrows. Sows show their best qualities in 2-5 farrowings.

The search for reserves for increasing the duration of the use of sows and obtaining the maximum number of piglets has become an urgent direction of research [2].

The research was carried out using the database of Plemzavod-Yubileiny, Tyumen region. Gilts of large white breed were studied. The following indicators were taken into account: the age of the first insemination, the number of gilts with abortion in different periods, the number of born and live piglets [3].

To identify the relationship between age and productivity, a grouping of gilts was carried out [4].

\section{Results and discussion}

The pigs were divided into groups according to the age of the first insemination. The results are shown in Table 1. 
Table 1. Grouping of gilts according to the age of the first insemination.

\begin{tabular}{|c|c|c|c|c|c|c|c|c|c|}
\hline \multirow{2}{*}{ อั๋ } & \multirow{2}{*}{ 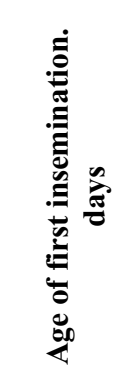 } & \multirow{2}{*}{ 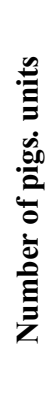 } & \multirow{2}{*}{ 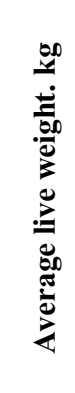 } & \multicolumn{3}{|c|}{ 志 } & \multirow{2}{*}{ 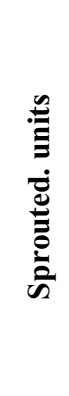 } & \multicolumn{2}{|c|}{ 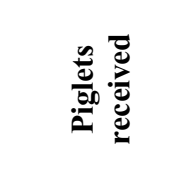 } \\
\hline & & & & ฮี & 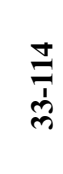 & 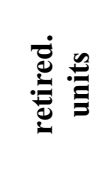 & & 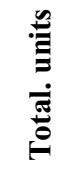 & 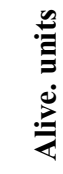 \\
\hline \multicolumn{10}{|c|}{2017} \\
\hline I & $217-228$ & 27 & 147 & 7 & 2 & 1 & 17 & 190 & 179 \\
\hline II & $229-240$ & 46 & 153 & 8 & 4 & 4 & 30 & 306 & 278 \\
\hline III & $241-253$ & 36 & 157 & 6 & 7 & 4 & 19 & 238 & 222 \\
\hline IV & $254-267$ & 20 & 166 & 2 & 3 & 2 & 13 & 151 & 138 \\
\hline $\mathrm{V}$ & $268-280$ & 8 & 170 & 1 & 1 & 1 & 5 & 50 & 47 \\
\hline VI & $281-311$ & 9 & 195 & 1 & - & - & 8 & 102 & 100 \\
\hline \multicolumn{10}{|c|}{2018} \\
\hline I & $212-229$ & 60 & 141 & $\begin{array}{l}1 \\
2\end{array}$ & 3 & 3 & 42 & 469 & 445 \\
\hline II & $230-241$ & 54 & 149 & 9 & 2 & 3 & 39 & 417 & 377 \\
\hline III & $242-253$ & 32 & 160 & 6 & 3 & 3 & 20 & 237 & 215 \\
\hline IV & $257-268$ & 14 & 166 & 2 & 2 & 2 & 8 & 99 & 95 \\
\hline $\mathrm{V}$ & $270-277$ & 4 & 180 & - & - & - & 4 & 41 & 40 \\
\hline \multicolumn{10}{|c|}{2019} \\
\hline $\mathrm{I}$ & $209-229$ & 84 & 138 & 4 & 5 & 4 & 66 & 735 & 672 \\
\hline II & $230-241$ & 54 & 146 & 3 & 2 & 2 & 47 & 516 & 487 \\
\hline III & $242-254$ & 19 & 158 & - & 2 & 2 & 13 & 148 & 130 \\
\hline IV & $255-265$ & 7 & 161 & - & - & - & 7 & 61 & 59 \\
\hline $\mathrm{V}$ & $268-304$ & 3 & 177 & - & - & - & 3 & 29 & 29 \\
\hline \multicolumn{10}{|c|}{2020} \\
\hline I & $211-229$ & 82 & 143 & 4 & 6 & 6 & 64 & 710 & 704 \\
\hline II & $230-241$ & 75 & 153 & 5 & 5 & 5 & 60 & 672 & 660 \\
\hline III & $242-254$ & 14 & 159 & 4 & 2 & 1 & 7 & 96 & 94 \\
\hline IV & $256-268$ & 7 & 169 & 2 & 1 & 1 & 3 & 38 & 37.5 \\
\hline $\mathrm{V}$ & $271-288$ & 3 & 190 & 1 & 1 & - & 1 & 12 & 12 \\
\hline
\end{tabular}

Note: the data was processed in the spreadsheet editor M. Excel package "Data Analysis", confidence level $\mathrm{P} \leq 0,95$.

Analysis of the results of insemination of large white pigs for 4 years (2017-2020) showed that the age began to decrease with each subsequent year. So in 2017, the fluctuations in the age of the first insemination were $\min -217$ days, max -311 days, the interval within the group was 11 days. The largest number of 102 gilts, out of 146 units were inseminated in the period from 229 days to 267 days. From 102 gilts (II, III, IV groups) 62 units farrowed, 695 piglets were obtained from them, live -638 units [9].

It should be noted that the pigs of the I group, inseminated at the age of 217-228 days, had a high rate of born piglets of 11.2 per farrowing. While the pigs of group II -10.2 , group III -12.5 , group IV -10.6 , group V -10.0 , group VI -12.7 . The largest number of piglets born was observed in group III - 12.5 units, where the age of the first insemination was 241-253 days and in group VI - 12.7, where the age of the first insemination was 281311 days. 
In 2018 , the age of the first insemination was $\min -212$ days, $\max -277$ days, the interval within the group was 17 days. The largest number of 164 gilts, out of 164 units were inseminated in the period from 212 days to 277 days. Of the 164 gilts (groups I, II, III), 101 units were farrowed, 1123 piglets were obtained from them, live - 1037 units. In terms of one farrowing, it was obtained in group I - 11.2, in group II - 10.7, in group III 11.8 , in group IV -12.4 , in group $\mathrm{V}-10.2$. The largest number of piglets born was observed in group IV (12.4 units), where the age of the first insemination was 257-268 days.

In 2019, the variability in the age of the first insemination was min - 209 days, max 304 days, the interval within the group was 11 days. The largest number of 157 gilts, out of 167 units were inseminated in the period from 209 days to 304 days. Of 157 gilts (groups I, II, III), 126 units were farrowed, 1399 pigs were obtained from them, live - 1289 units. In terms of one farrowing, it was obtained in group I - 11.1, in group II - 10.9, in group III -11.4 , in group IV -8.7 , in group $\mathrm{V}-9.6$. The largest number of piglets born was observed in group III, 11.4 units, where the age of the first insemination was 242-253 days.

In 2020, the age of the first insemination ranged from min - 211 days to max -288 days, the interval within the group was 18 days. The largest number of 171 gilts, out of 181 units were inseminated in the period from 211 days to 288 days. Of 171 pigs (groups I, II, III), 131 units were farrowed, 1478 piglets were obtained from them, of which 1458 were live. In terms of one farrowing, it was obtained in group I - 11.1, in group II - 11.2, in group III - 13.7, in group IV - 12.7, in group V - 12.0. The largest number of piglets born was observed in group III, 13.7 units, where the age of the first insemination was 242-254 days (8-8.4 months).

An analysis of the insemination of gilts and its effectiveness in the period from 2017 to 2020 was carried out. (fig. 1).

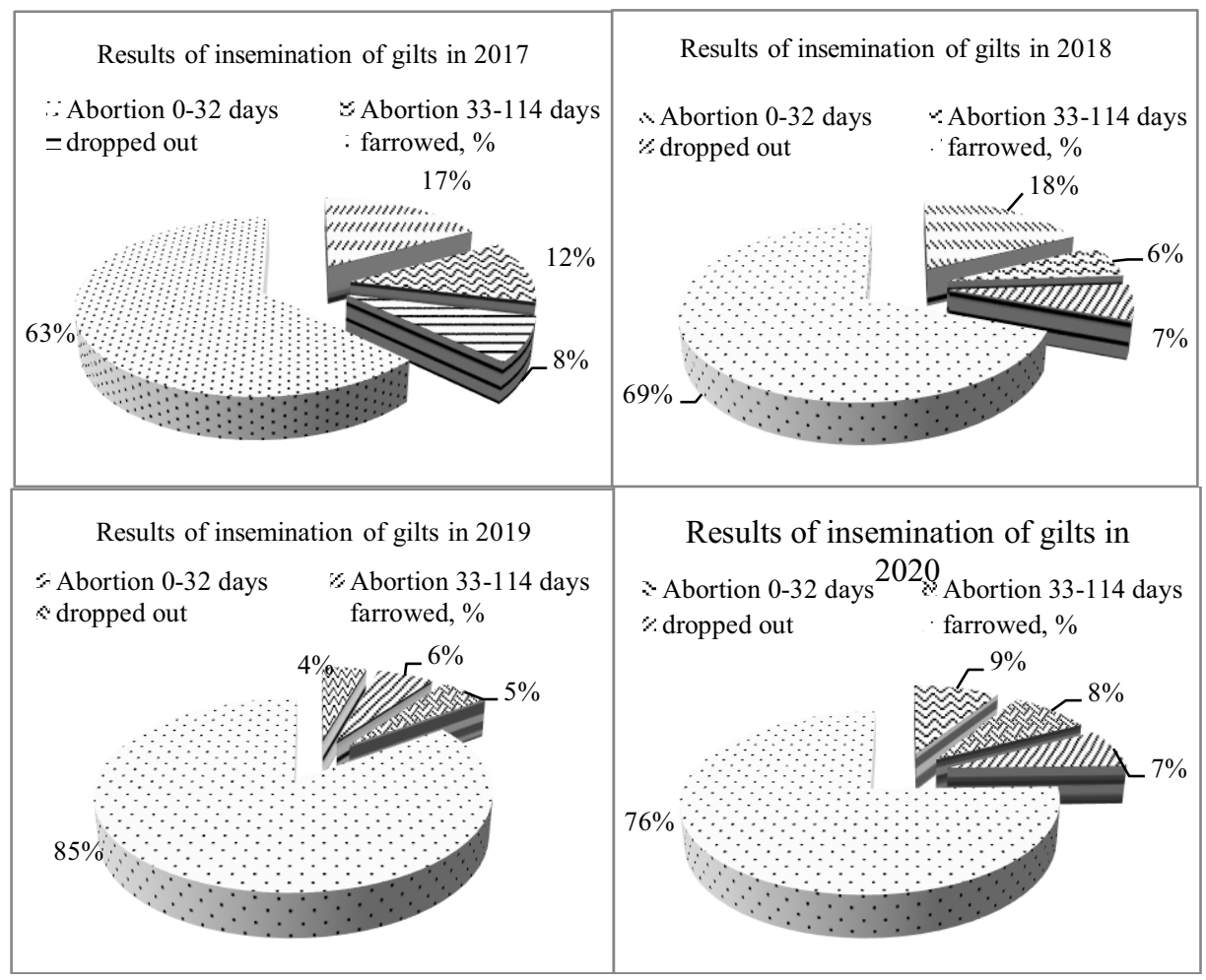

Fig. 1. Dynamics of the results of insemination of pigs. 
There was a positive trend in the percentage of gilts farrowing in 2019-2020. compared to $2017-2018$ In 2020 , there is a decrease by $8 \%$ in violations in the first half of pregnancy ( 0 to 32 days), by $4 \%$ in the second half of pregnancy (33-114 days), leading to abortion compared to 2017 . It should be noted that the number of sows with terminated pregnancies in the studied years was uneven, which may be explained by the influence of various environmental, technological and other factors [5,6].

The study of the percentage of inseminations of gilts and the results of surveys, depending on the age of the first insemination, is shown in the graphs (Fig. 2).

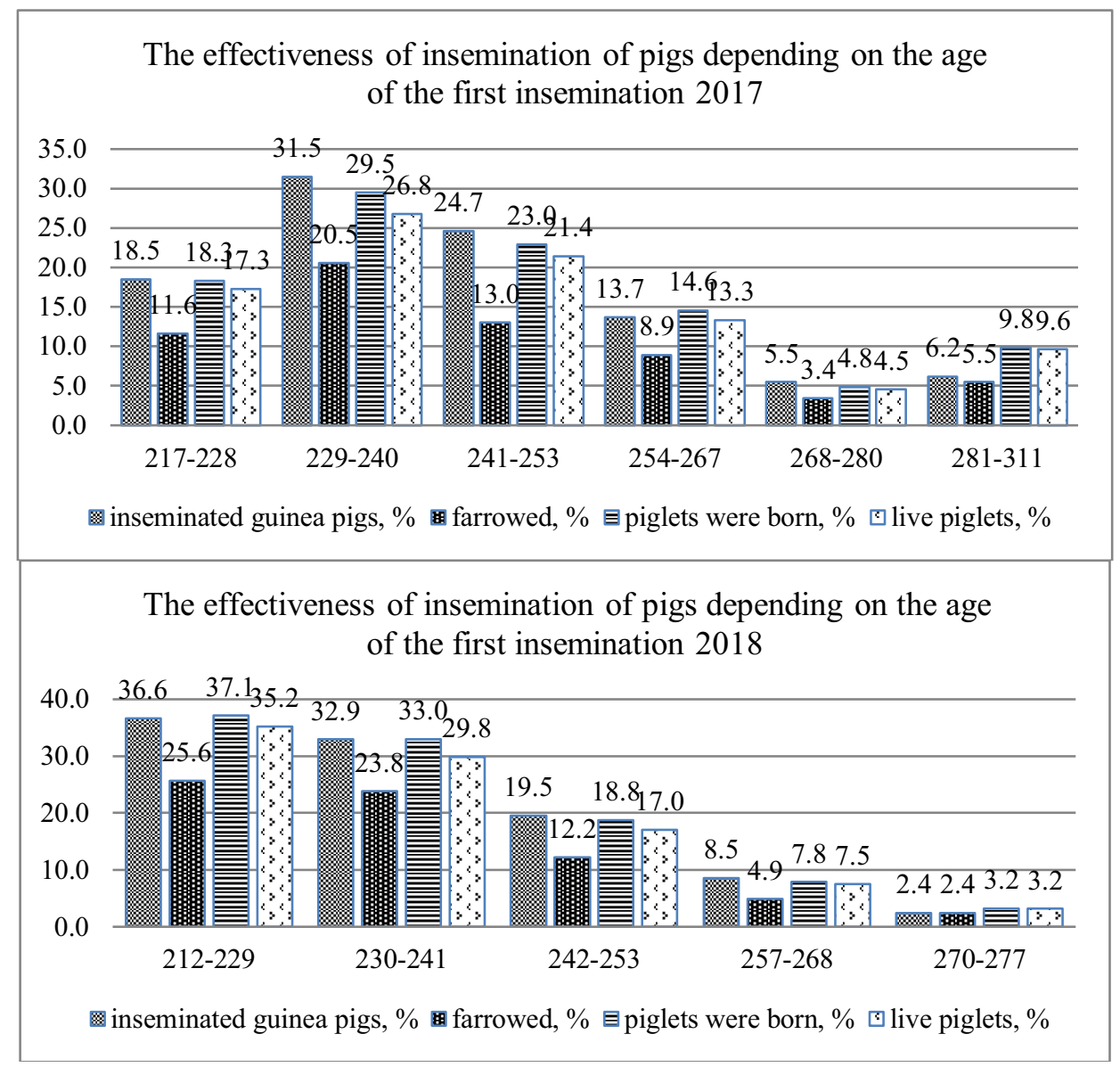




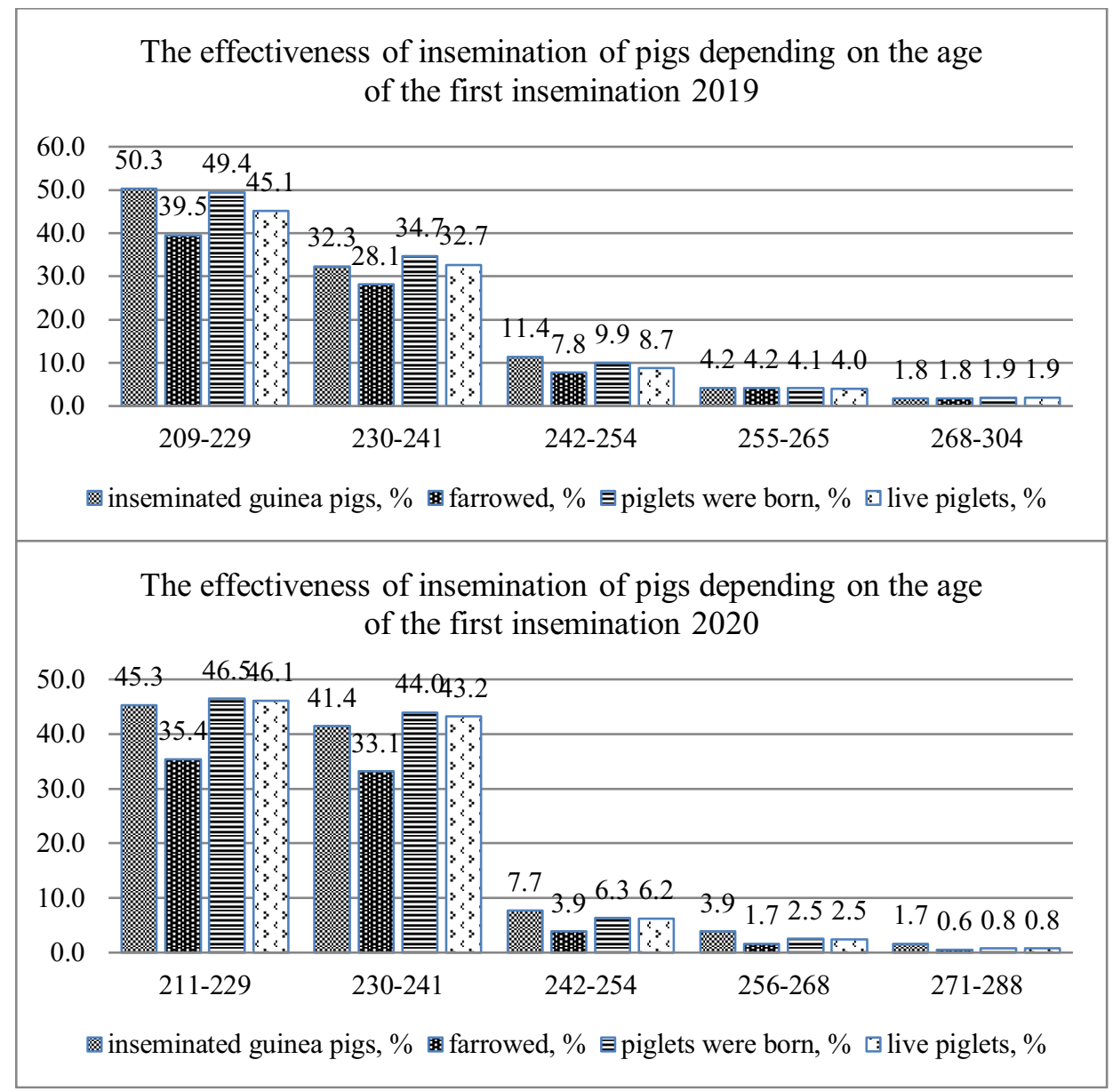

Fig. 2. Efficiency of insemination of pigs depending on the age of the first insemination.

During the period of $2017,18.5 \%$ of pigs were inseminated in group I, of which $11.6 \%$ farrowed, $18.3 \%$ of piglets were born, of which $17.3 \%$ are alive; in group II, 31.5 were inseminated, $20.5 \%$ of them farrowed, $29.5 \%$ of piglets were born, of which $26.8 \%$ were alive; in group III, $24.7 \%$ of gilts were inseminated, $13.0 \%$ of them farrowed, $23 \%$ of piglets were born, of which $21.4 \%$ were alive; in group IV, $13.7 \%$ were inseminated, of which $8.9 \%$ farrowed, $14.6 \%$ of piglets were born, of which $13.3 \%$ were alive. The composition of groups V and VI is small, which affected the percentage of inseminated and farrowed 5-6\%, born and live piglets $4.8-4.5$ and $9.8-9.6 \%$, respectively.

In the period of 2018 , in group I, $36.6 \%$ of gilts were inseminated, of which $25.6 \%$ farrowed, $37.1 \%$ of piglets were born, of which $35.2 \%$ are alive; in group II 32.9 were inseminated, $23.8 \%$ of them farrowed, $33.0 \%$ of piglets were born, of which $29.8 \%$ were alive; in group III, $19.5 \%$ of gilts were inseminated, $12.2 \%$ of them farrowed, $18.8 \%$ of piglets were born, $17.0 \%$ of them were live; in group IV, 8.5 were inseminated, of which $4.9 \%$ farrowed, $7.8 \%$ of piglets were born, of which $7.5 \%$ were alive, in group $\mathrm{V}$ there were 4 gilts at the age of 270-277 days, which amounted to $2.4 \%$ all of them farrowed and $3.2 \%$ live piglets were obtained.

In the period of $2019,50.3 \%$ of gilts were inseminated in group I, of which $39.5 \%$ farrowed, $49.4 \%$ of piglets were born, of which $45.1 \%$ are alive; in group II 32.3 were inseminated, $28.1 \%$ of them farrowed, $34.7 \%$ of piglets were born, of which $32.7 \%$ were 
alive; in group III, $11.4 \%$ of pigs were inseminated, of which $7.8 \%$ farrowed, $9.9 \%$ of piglets were born, of which $8.7 \%$ were live; in group IV, 4.2 were inseminated, all farrowed, piglets were born $4.1 \%$, of which $4.0 \%$ were alive, in group V there were 3 gilts aged 268-304 days, which amounted to $1.8 \%$, all of them farrowed and received $1.9 \%$ of live piglets $[10,11]$.

In the period of $2020,45.3 \%$ of pigs were inseminated in group I, 35.4\% of them farrowed, $46.5 \%$ of piglets were born, of which $46.1 \%$ were alive; in group II, 41.4 were inseminated, $33.1 \%$ of them farrowed, $44.0 \%$ of piglets were born, of which $43.2 \%$ were alive; in group III, $7.7 \%$ of pigs were inseminated, $3.9 \%$ of them farrowed, $6.3 \%$ of piglets were born, of which $6.2 \%$ were live; in group IV $3.9 \%$ were inseminated, $1.7 \%$ farrowed, $2.5 \%$ piglets were born, in group $\mathrm{V}$ there were 3 gilts aged 271-288 days, which amounted to $1.7 \%$ of them farrowed $0.6 \%$, received $0,8 \%$ live pigs.

Graphical analysis showed that the first insemination of gilts is observed at a younger age of 7-9.6 months. (211-288 days) in 2020 compared to 7.3-10.4 months. (217-311 days) in 2017. The largest number of gilts, $86.7 \%$, were inseminated at the age of 7 to 8 months, of which $68.5 \%$ farrowed, $90.5 \%$ of piglets were born, including $89.3 \%$ live. This is due to the introduction into the herd of gilts of specialized mother breeds with high vigor of growth and development, capable of showing high productivity $[7,8]$.

\section{Output}

There was a positive trend in the percentage of gilts farrowing in 2020 compared to 2017. In 2020 , there is a decrease by $8 \%$ in violations in the first half of pregnancy ( 0 to 32 days), by $4 \%$ in the second half of pregnancy (33-114 days), leading to abortion compared to 2017. The number of sows with terminated pregnancies in the studied years was uneven, which may be explained not by the ages of the first insemination, but by the influence of various environmental, technological and other factors [12].

A decrease in the age of the first insemination of gilts was noted, so in 2020 gilts were inseminated at a younger age of 7-9.6 months. (211-288 days) versus 7.3-10.4 months. (217-311 days) pigs in 2017. Analysis of the age of first insemination and the number of piglets obtained showed that the largest number of gilts, $86.7 \%$, were inseminated at the age of 7 to 8 months, of which $68.5 \%$ farrowed, $90.5 \%$ of piglets were born, including $89.3 \%$ alive. This is due to the introduction into the herd of gilts of specialized mother breeds with high vigor of growth and development, capable of showing high productivity.

The minimum age for the first insemination of Large White gilts was 209 days in 2019, that is, 6.9 months. the average live weight is $138 \mathrm{~kg}$, from them 11.1 piglets were received per one farrowing. It should also be noted that gilts bred at the age of 217-228 days had a high birth rate of 11.2 piglets per farrowing in 2017. High rates of received piglets 13.7 per one farrowing were noted in gilts bred at 242-254 days, that is, 8-8.4 months. According to the research results, the most optimal age of the first insemination can be considered 7-8 months $[13,14,15]$.

\section{References}

1. O.L. Tretyakova, Polythematic network electronic scientific journal of the Kuban State Agrarian University 134, 514-524 (2017)

2. M.S. Brar, Journal of General Virology 96(7), 1570-1580 (2015)

3. Engblom Animal Industry report. Iowa State Universite 56, 86-89 (2010)

4. I.S. Frydas, Vet. Res 44, 132-134 (2013) 
5. Haimi-Hakala, Porcine Health Manag 23, 19 (2017)

6. A.M. Jamieson, Science 340, 1230-1234 (2013)

7. Kiwon Han, Clinical and vaccine immunology 10, 1600-1607 (2011)

8. S.H. Kim, Veterinary Microbiology 143, 394-400 (2010)

9. B. Close, Animal Husbandry of Russia 10, 29-30 (2014)

10. J.H. Lee, Asian-Australasian Journal of Animal Science 28(10), 1388-1393 (2015)

11. D. Lucac, African Journal of Agricultural Research 8(37), 4664-4669 (2013)

12. C. Leng, Vet Immunol Immunopathol 15, 65-71 (2014)

13. J.K. Liu, Transbound Emerg Dis. 64(6), 2059-2074 (2017)

14. D. Radojkovic, Belgrade-Zeman: Biotechnology in Animal Husbandry. Institute for Animal Husbandry 27(3), 777-783 (2011)

15. L. Zhang, PLoS One 11(5), 1542 (2016) 